\title{
Evaluation of non-invasive imaging parameters in coronary microvascular disease: a systematic review
}

\author{
F. Groepenhoff ${ }^{1,2 \dagger}{ }^{\dagger}$, R. G. M. Klaassen ${ }^{1 \dagger}$, G. B. Valstar ${ }^{1}$, S. H. Bots ${ }^{1}$, N. C. Onland-Moret ${ }^{3}$, H. M. Den Ruijter ${ }^{1}$, \\ T. Leiner ${ }^{4}$ and A. L. M. Eikendal ${ }^{1^{*}}$
}

\begin{abstract}
Background: Coronary microvascular dysfunction (CMD) is an important underlying cause of angina pectoris. Currently, no diagnostic tool is available to directly visualize the coronary microvasculature. Invasive microvascular reactivity testing is the diagnostic standard for CMD, but several non-invasive imaging techniques are being evaluated. However, evidence on reported non-invasive parameters and cut-off values is limited. Thus, we aimed to provide an overview of reported non-invasive parameters and corresponding cut-off values for CMD.
\end{abstract}

Methods: Pubmed and EMBASE databases were systematically searched for studies enrolling patients with angina pectoris without obstructed coronary arteries, investigating at least one non-invasive imaging technique to quantify CMD. Methodological quality assessment of included studies was performed using QUADAS-2.

Results: Thirty-seven studies were included. Ten cardiac magnetic resonance studies reported MPRI and nine positron emission tomography (PET) and transthoracic echocardiography (TTE) studies reported CFR. Mean MPRI ranged from $1.47 \pm 0.36$ to $2.01 \pm 0.41$ in patients and from $1.50 \pm 0.47$ to $2.68 \pm 0.49$ in controls without CMD. Reported mean CFR in PET and TTE ranged from $1.39 \pm 0.31$ to $2.85 \pm 1.35$ and $1.69 \pm 0.40$ to $2.40 \pm 0.40$ for patients, and $2.68 \pm 0.83$ to $4.32 \pm 1.78$ and $2.65 \pm 0.65$ to $3.31 \pm 1.10$ for controls, respectively.

Conclusions: This systematic review summarized current evidence on reported parameters and cut-off values to diagnose CMD for various non-invasive imaging modalities. In current clinical practice, CMD is generally diagnosed with a CFR less than 2.0. However, due to heterogeneity in methodology and reporting of outcome measures, outcomes could not be compared and no definite reference values could be provided.

Keywords: Coronary microvascular dysfunction, Non-invasive imaging, Reference values, Coronary flow reserve, Myocardial perfusion reserve

*Correspondence: a.Im.eikendal@umcutrecht.nl

${ }^{\dagger}$ F. Groepenhoff and R. G. M. Klaassen have contributed equally

1 Laboratory of Experimental Cardiology, University Medical Center Utrecht, Utrecht University, Heidelberglaan 100, 3584 CX Utrecht, The Netherlands

Full list of author information is available at the end of the article

\section{Background}

Patients with angina pectoris (AP) often do not show significant obstructive coronary artery disease (CAD) on coronary angiography (CAG) [1, 2]. Consequently, a cardiac cause of AP complaints is frequently deemed unlikely. Yet, a significant fraction of these patients suffer from cardiac ischemia due to coronary microvascular dysfunction (CMD) [2-6], a condition associated with increased risk of adverse cardiovascular events. 
This emphasizes the importance of accurate diagnosis of CMD [2, 7-11].

The Coronary Vasomotion Disorders International Study Group (COVADIS) determined the following criteria to diagnose CMD: presence of symptoms and objective documentation of myocardial ischemia, absence of obstructive CAD $(<50 \%$ stenosis and/or fractional flow reserve $<0.8$ ) and confirmed reduced coronary flow reserve (CFR) (and/or inducible microvascular spasm). However, assessment of CMD remains challenging, as no tools are available to directly visualize the coronary microvasculature. In fact, the current golden standard to diagnose CMD is invasive measurement of CFR in epicardial arteries without functionally relevant stenosis [12]. The CFR depicts the increase in coronary blood flow in response to vasoactive agents $[2,4,9]$ and provides indirect quantification of coronary microvascular blood flow $[5,13]$.

The invasive nature and high costs of coronary reactivity testing (CRT) initiated the search for a non-invasive alternative to diagnose CMD, including myocardial perfusion reserve index (MPRI) measured using cardiac magnetic resonance imaging (CMR), and CFR using positron emission tomography (PET) and transthoracic echocardiography (TTE) [13-16]. Yet, the cut-off value for CFR to diagnose CMD differs between these modalities, is not well validated and, even though sex-differences in coronary physiology are known, the need for a sex-specific cut-off value remains under debate [17]. To date, a CFR below 2.0 to 2.5 is deemed diagnostic for CMD [9, $16,18-20]$.

The (dis)advantages of these non-invasive imaging techniques in the diagnosis of CMD have been discussed extensively before [21]. However, it is unclear which outcome parameters and corresponding cut-off values should be used to diagnose CMD. As such, this systematic review aims to provide an overview of currently reported reference and cut-off values for diagnosing CMD in a non-invasive manner.

\section{Methods}

\section{Search strategy}

On October 15, 2018 the PubMed and EMBASE databases were systematically searched for non-invasive imaging studies on CMD. The search was updated on November 1, 2020. Studies were considered for eligibility without date restriction. The search terms and synonyms of 'coronary microvascular dysfunction', 'nonobstructive coronary disease' and 'imaging', including the imaging modalities CMR, PET and TTE were used. A broad search strategy was performed as studies on CMD are limited and nomenclature of CMD is not standardized. Therefore, search terms were searched for in 'All Fields'
The detailed search strategy is provided in Additional file 1: Search Strategy.

\section{Study selection}

To assess eligibility, the results from the literature search were initially screened by title and abstract and subsequently for full text. Article selection and data extraction were performed independently by two reviewers (RGMK and FG). Observational studies and randomized controlled trials providing baseline outcome measurements were considered for inclusion.

Studies were included if they enrolled participants with AP (i.e. effort angina or anginal equivalents) and CAG or coronary computed tomography angiography confirmed absent or nonobstructive CAD (based on the definition described in the study protocol of the included studies), or healthy participants without prior history of cardiovascular disease or AP as a control group and reported the results of a non-invasive imaging method with use of pharmacological stress (i.e. flow parameters measured with either CMR, PET or TTE) to diagnose CMD.

Studies written in languages other than English or Dutch, exclusively consisting of participants with comorbidities, i.e. CAD, diabetes mellitus, aortic stenosis or cardiomyopathies, were excluded. Studies were excluded if outcomes were not reported as flow parameters, if patients were stratified according to the outcome of interest or if patient or control groups contained fewer than 10 participants.

\section{Quality assessment}

A methodological quality assessment was performed with the QUADAS-2 (Tool for the Quality Assessment of Diagnostic Accuracy Studies [22]). Studies were assessed for concerns of applicability ('low', 'high' or 'unclear') and for risk of bias ('low', 'high' or 'unclear') on four key domains (patient selection, index test, reference standard and flow and timing). The assessments per domain were combined into an overall risk of bias and concern of applicability.

\section{Data extraction and analysis}

The variables of interest were extracted using a standardized data collection form. Post-hoc evaluations within one clinical trial assessing the same imaging modality were considered as one study. Due to heterogeneity of the included studies, a meta-analysis of the results was not possible.

\section{Results}

Search results

The search yielded a total of 6976 results, 2568 studies in Pubmed and 4408 studies in Embase. Removal of 
duplicates resulted in 5238 unique entries. After title and abstract screening, 443 possibly relevant studies were obtained. The full texts of these studies were screened to select those that met the inclusion criteria as provided in the methods section. One relevant study was obtained through cross-reference checking. Thirty-seven studies met the inclusion criteria and were included in the final analysis. The search and inclusion and exclusion of relevant studies are summarized in Fig. 1. The characteristics of the included studies are summarized in Table 1. Quality assessment of included studies showed a clear description of the reference standard was not part of the study protocol in most of the included studies. The full assessment is provided in Additional file 2: Table S1 [22].

\section{Demographic information}

The number of patients included in each study was generally small, with a median study population of 22 patients (range 11 to $963,89 \%$ women) and median of 18 controls (range 10 to $268,33 \%$ women). The mean age in patient groups ranged from $50.0 \pm 7.0$ to $66.0 \pm 10.0$ years of age and $35.3 \pm 3.9$ to $62.6 \pm 9.1$ years of age in control groups. The specific demographic information per study is summarized in Table 1.

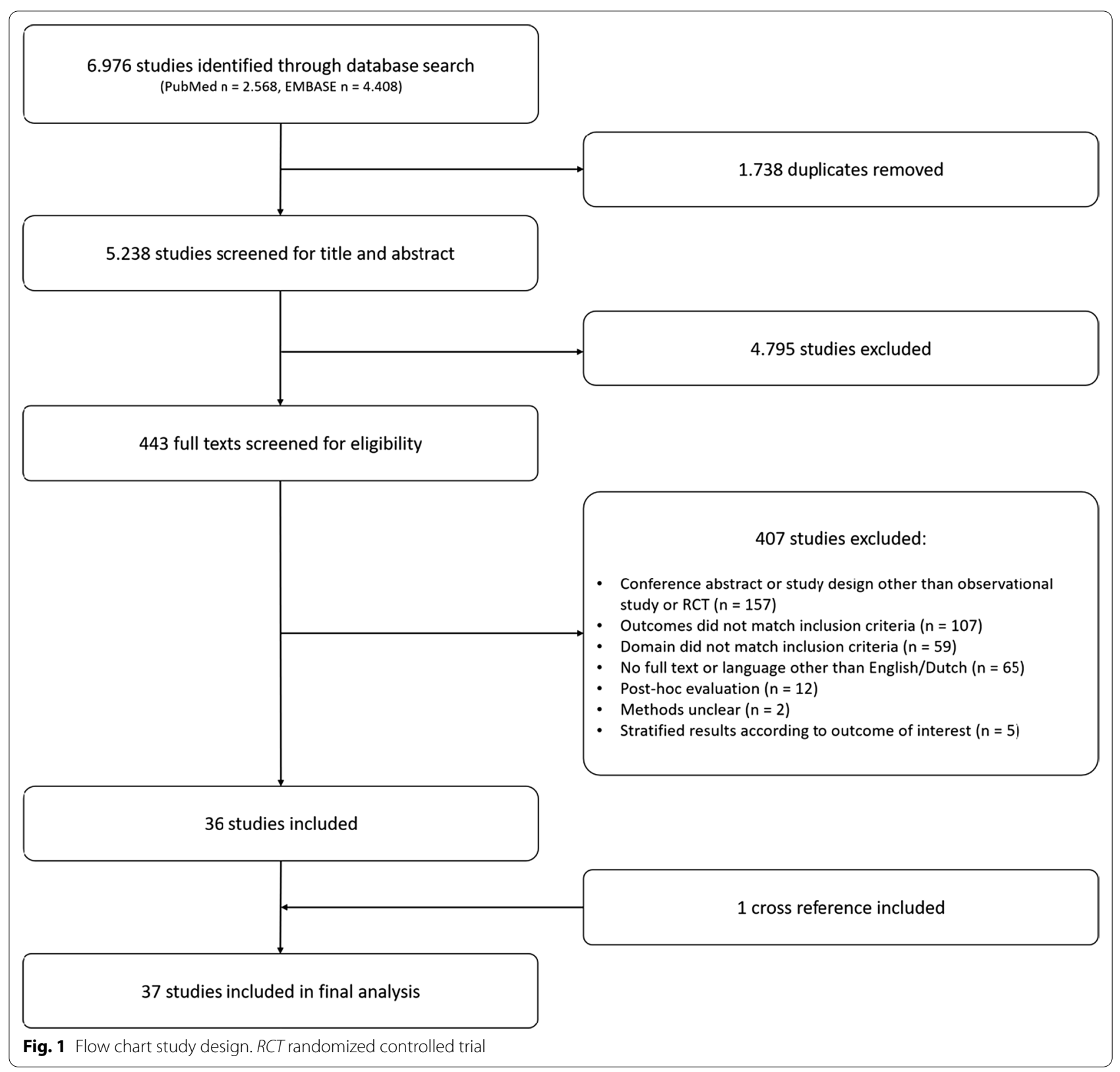




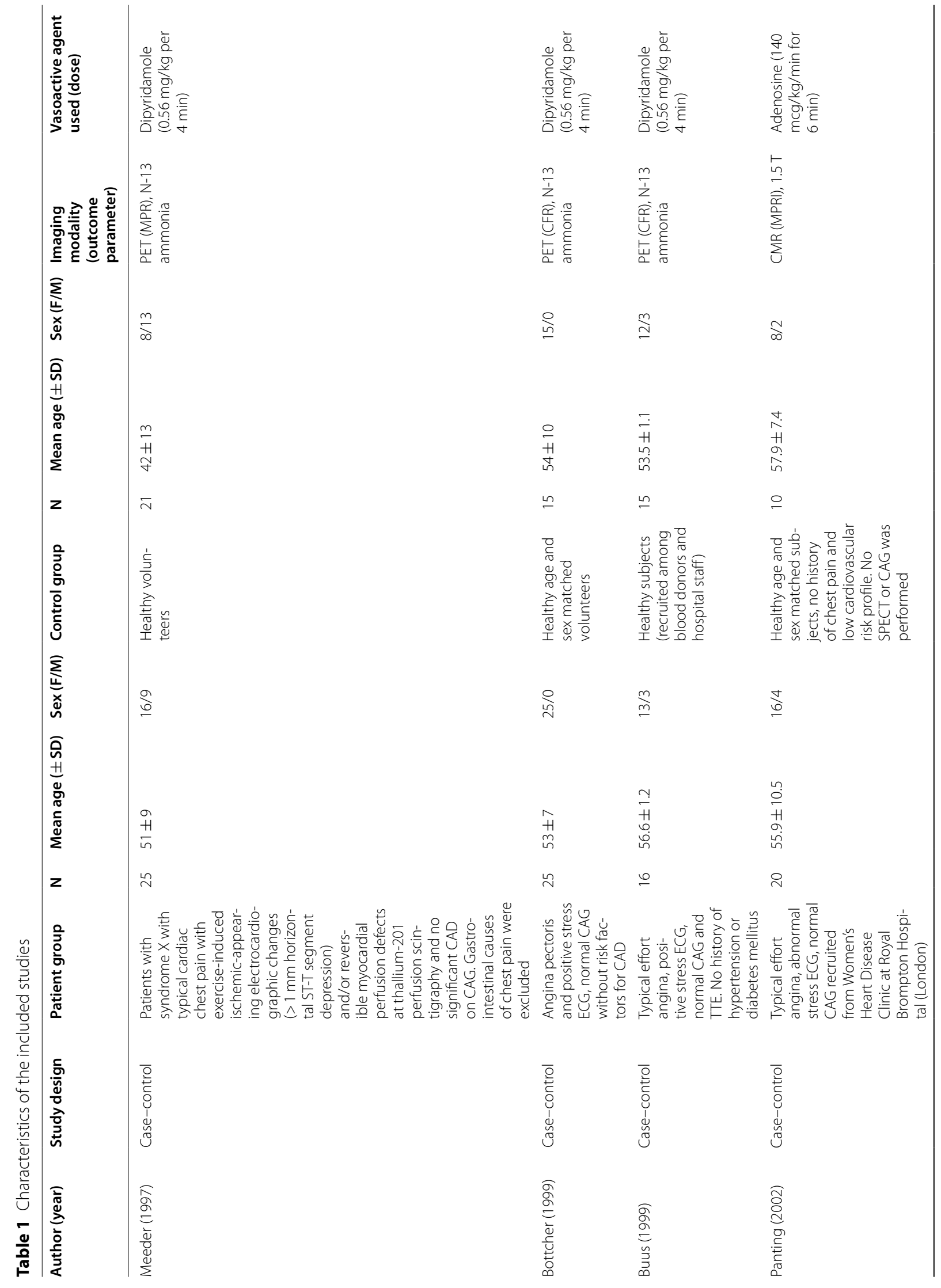




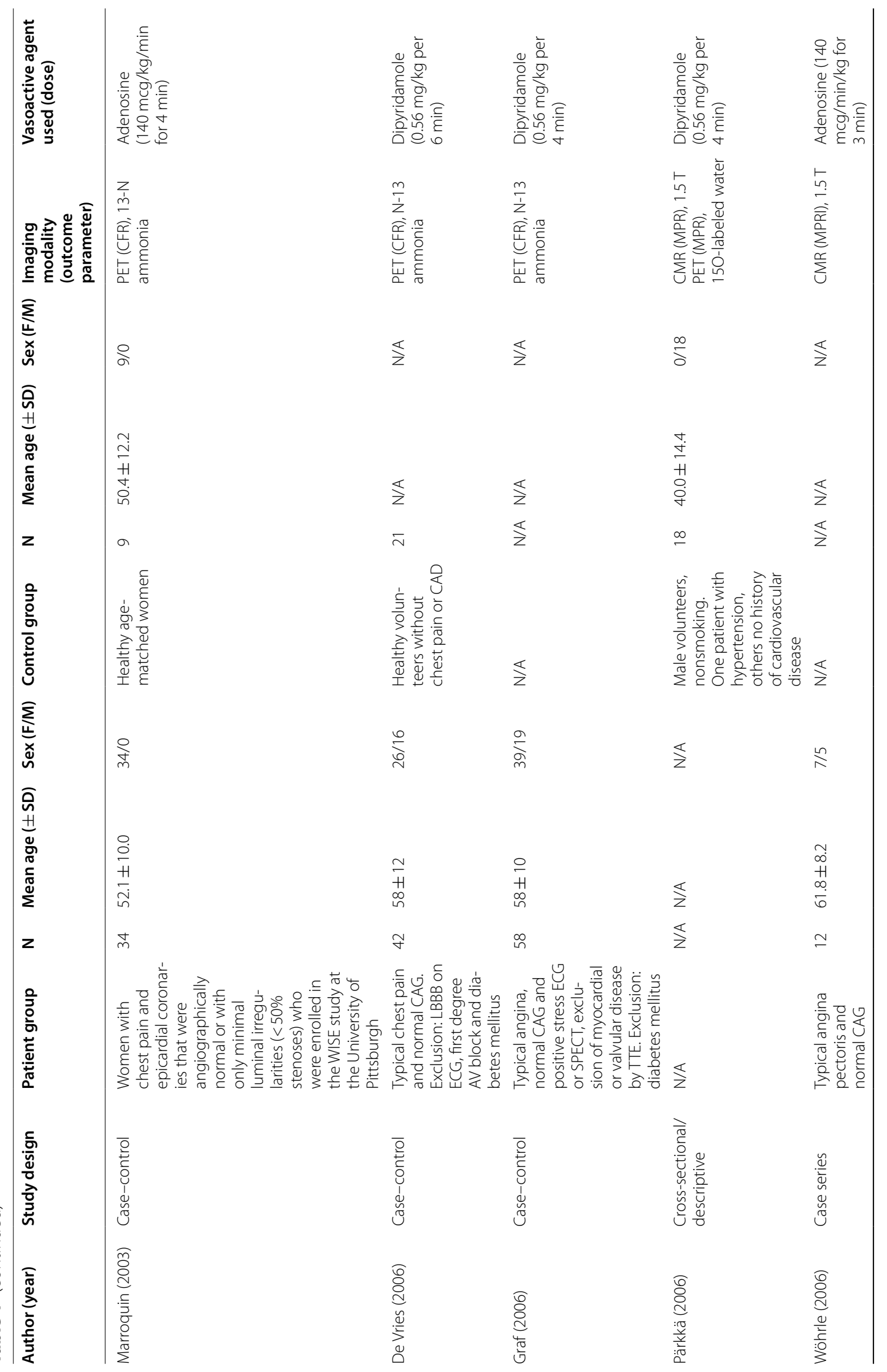




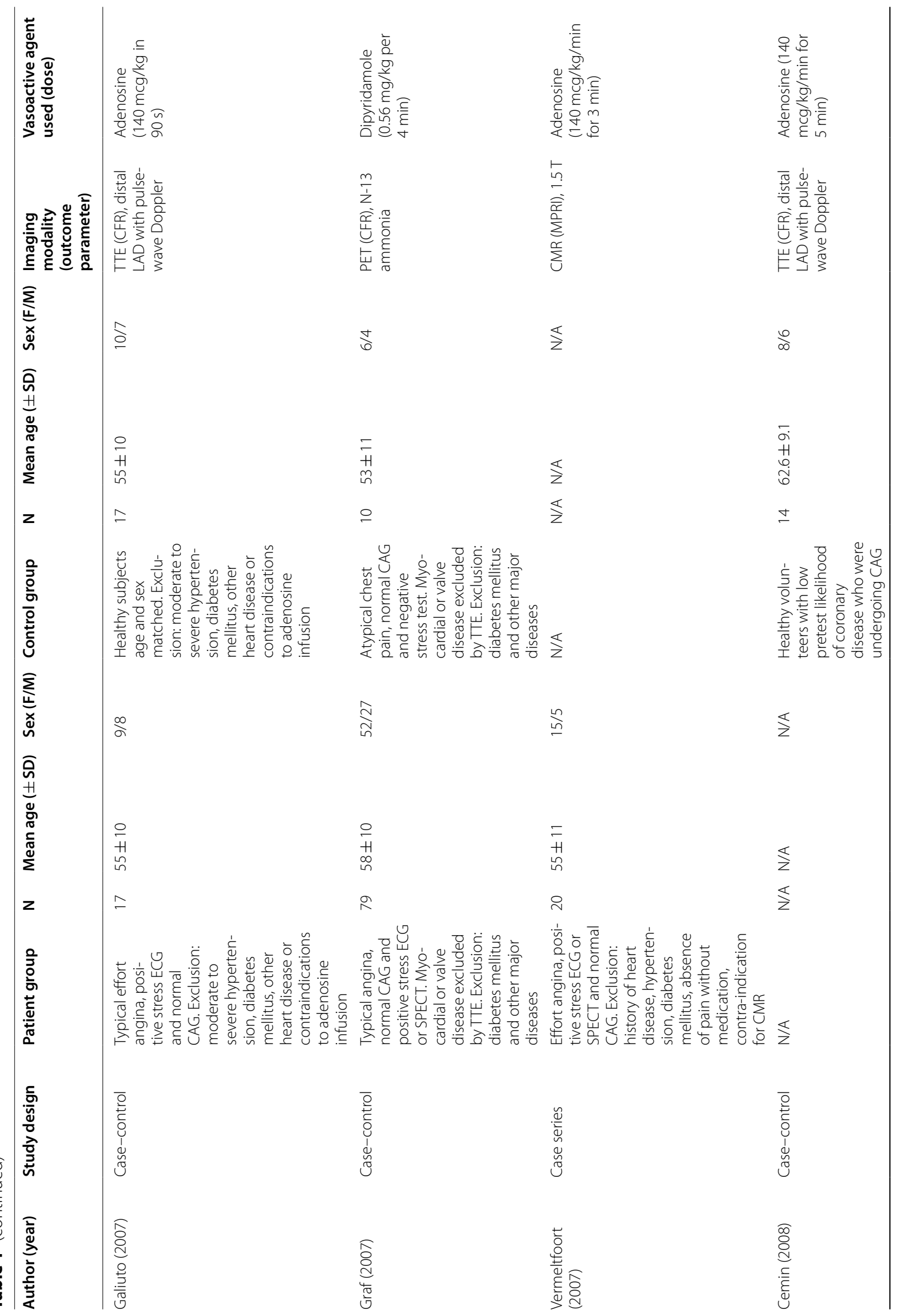




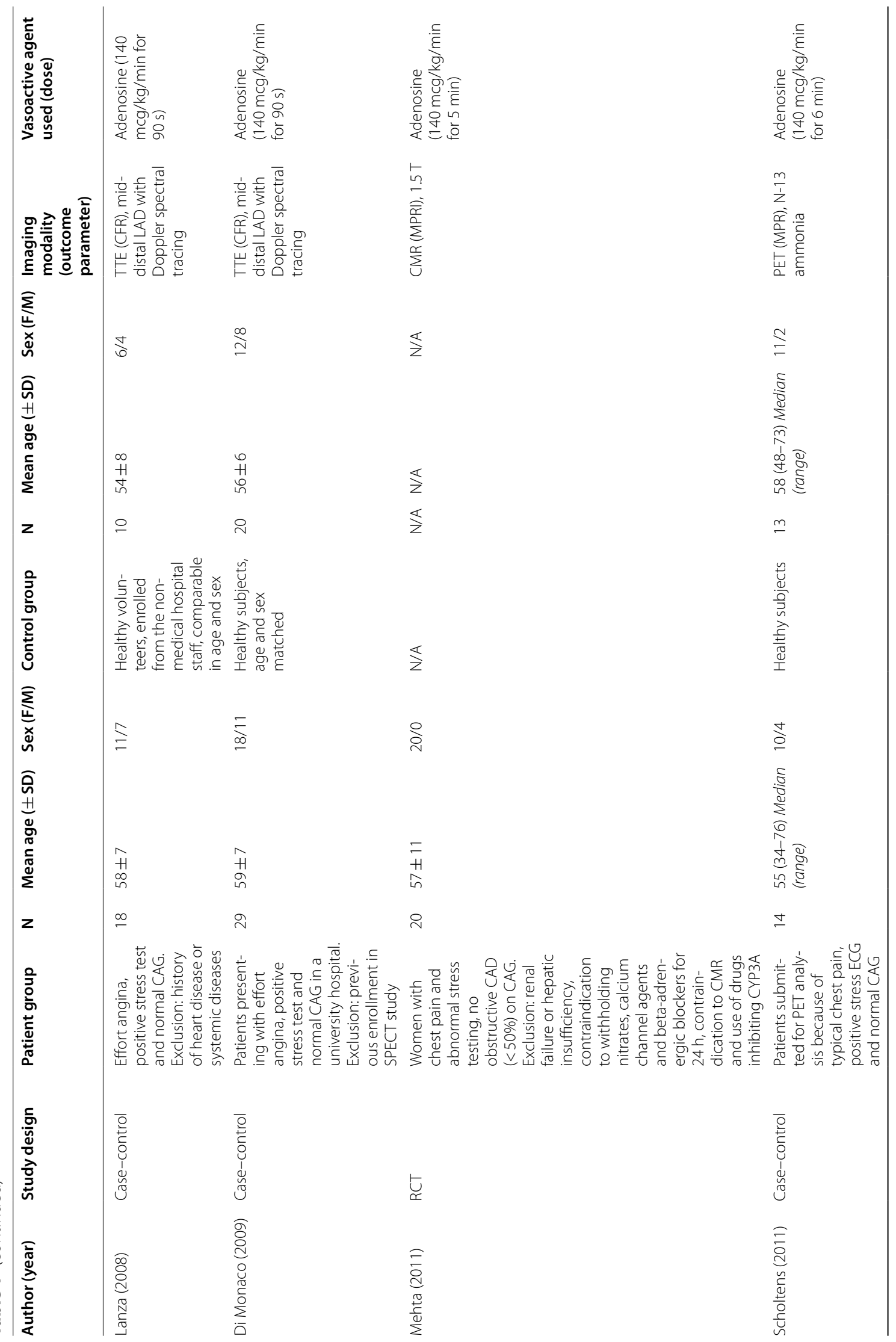




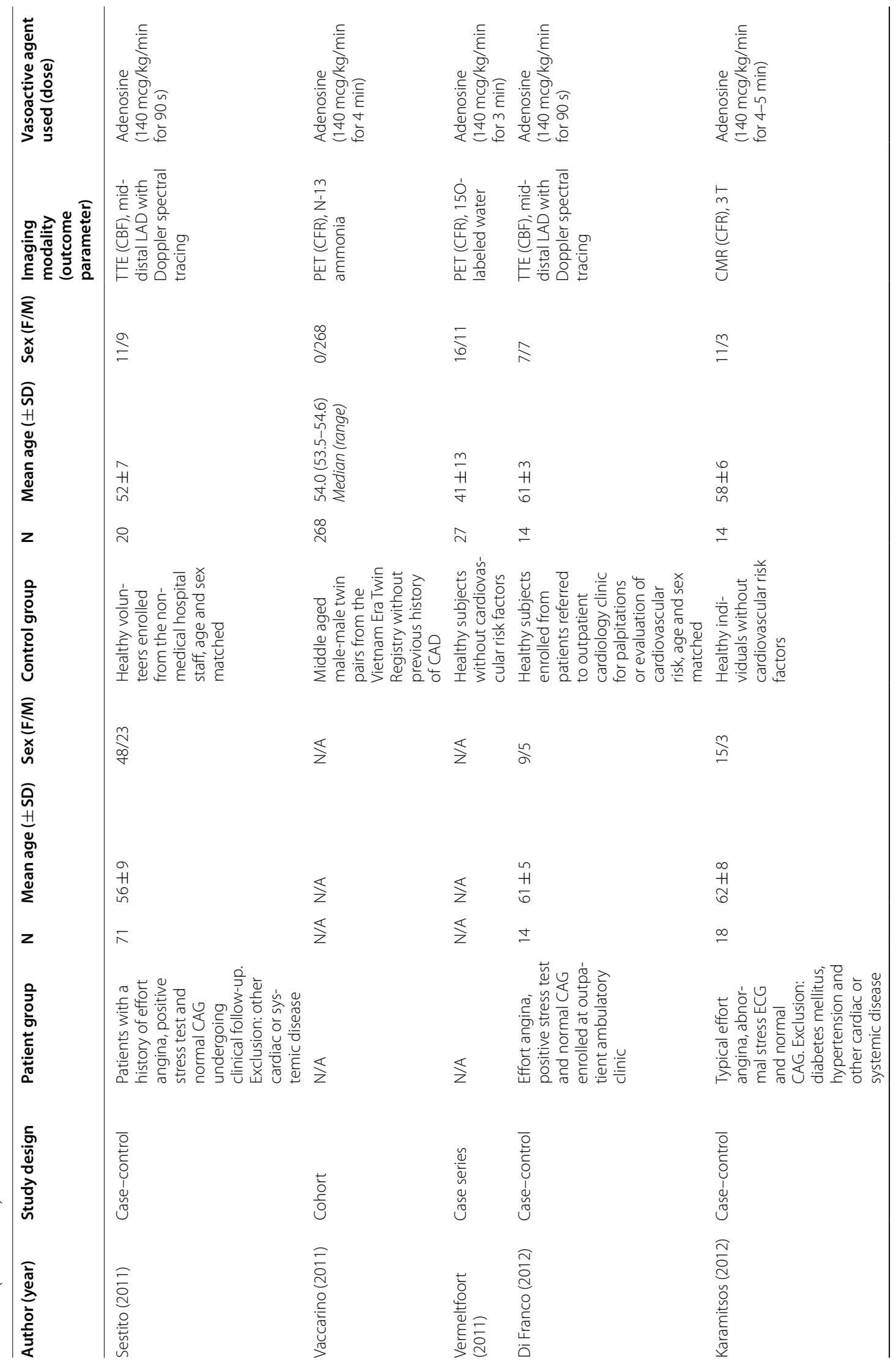




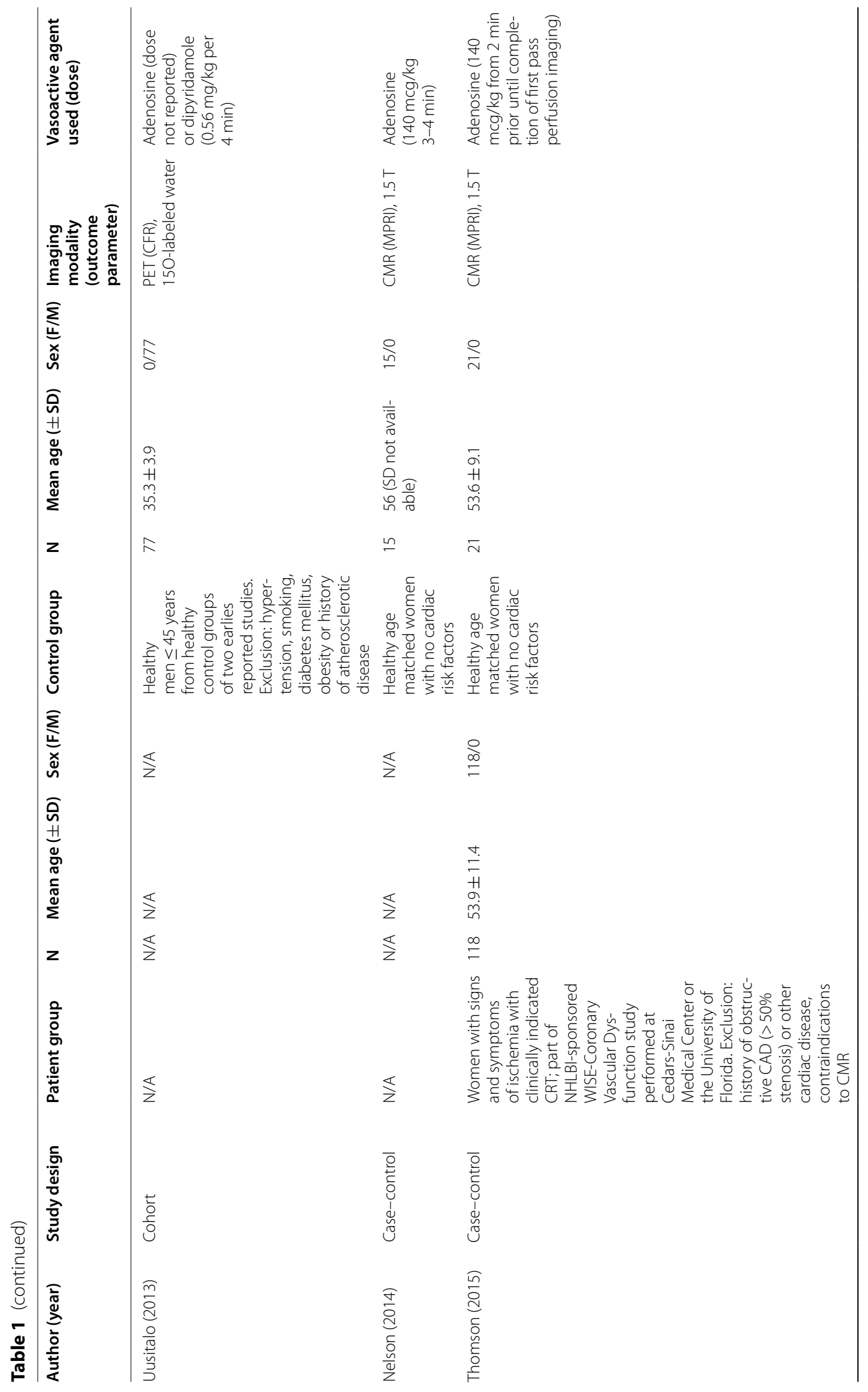




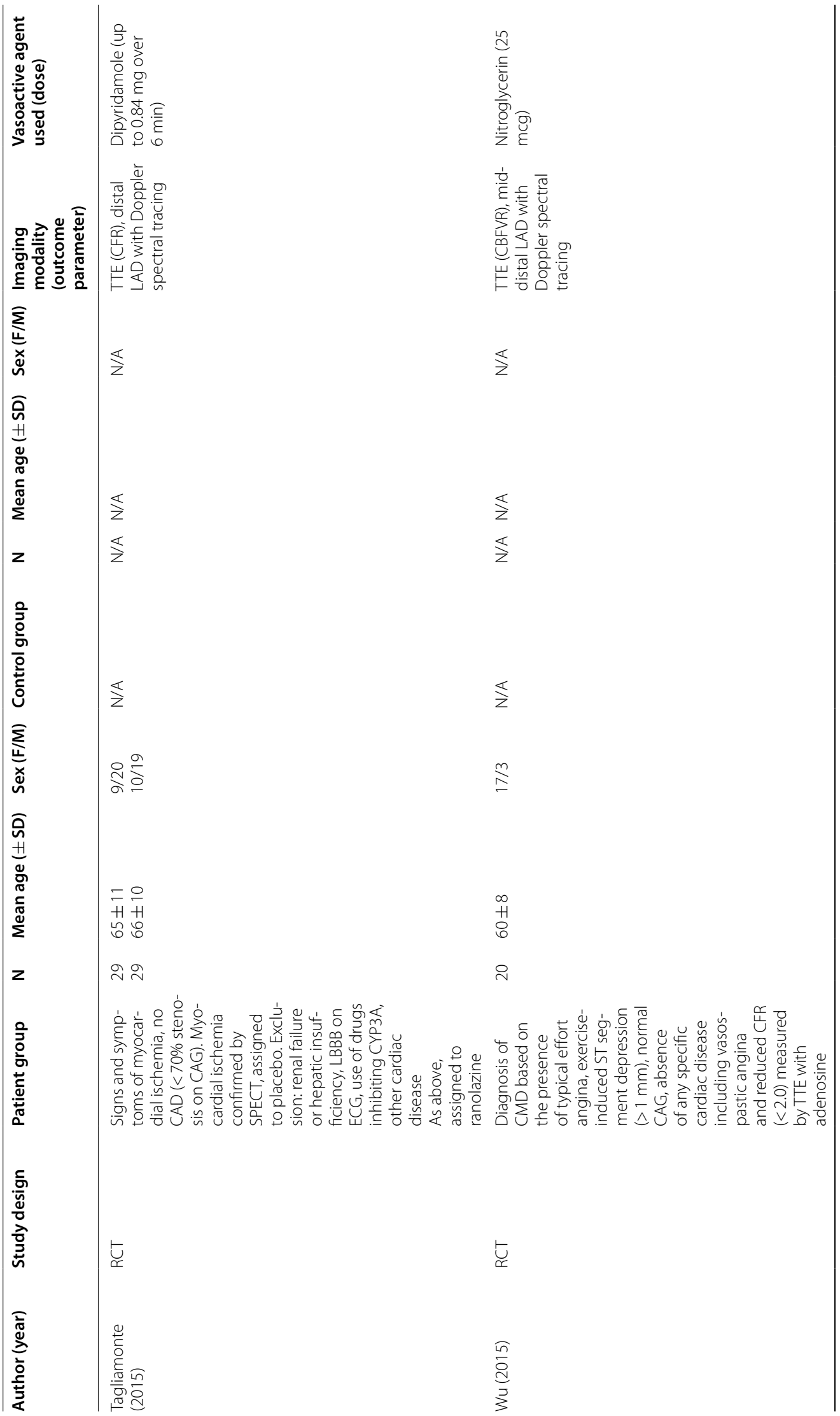




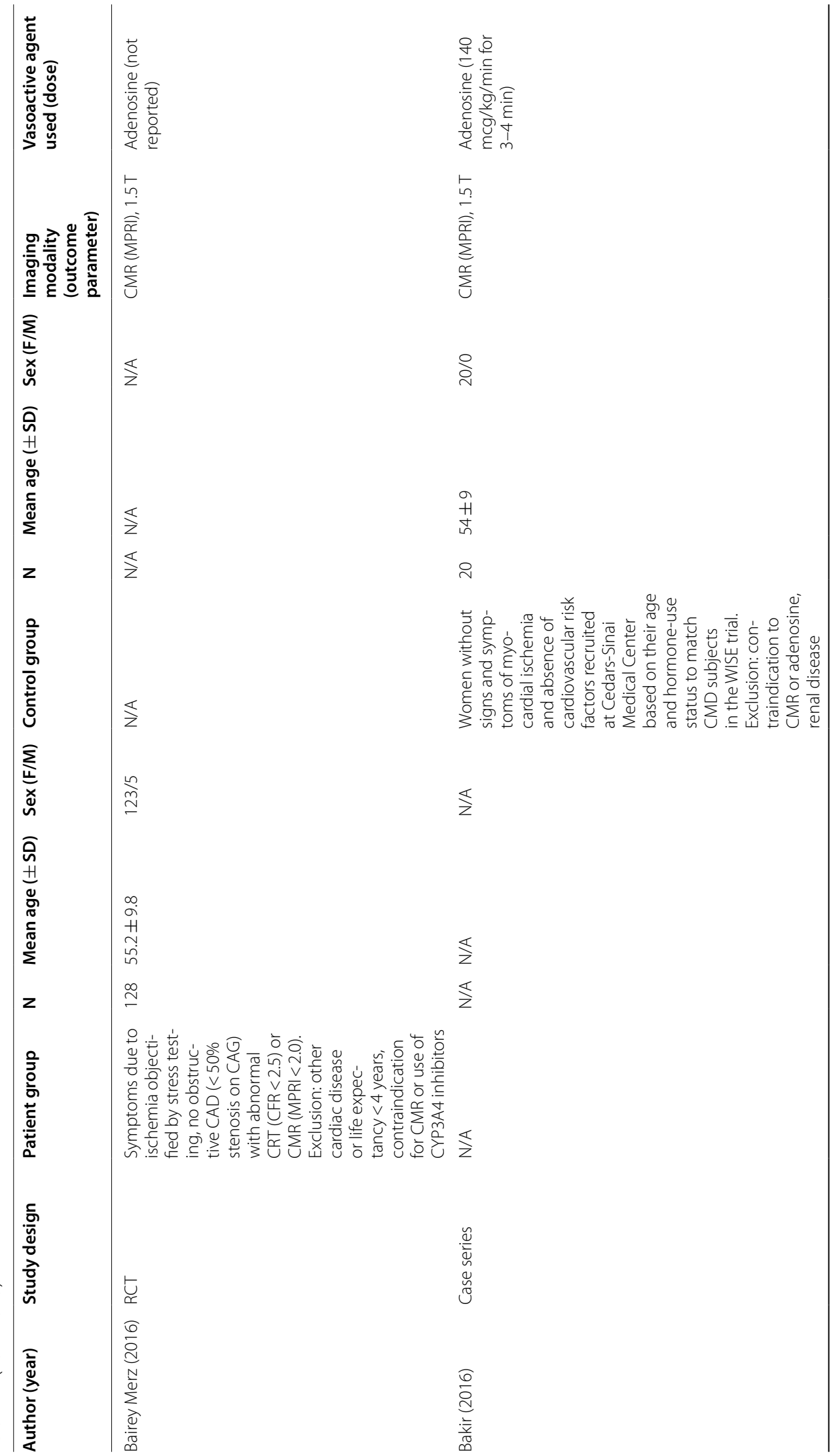




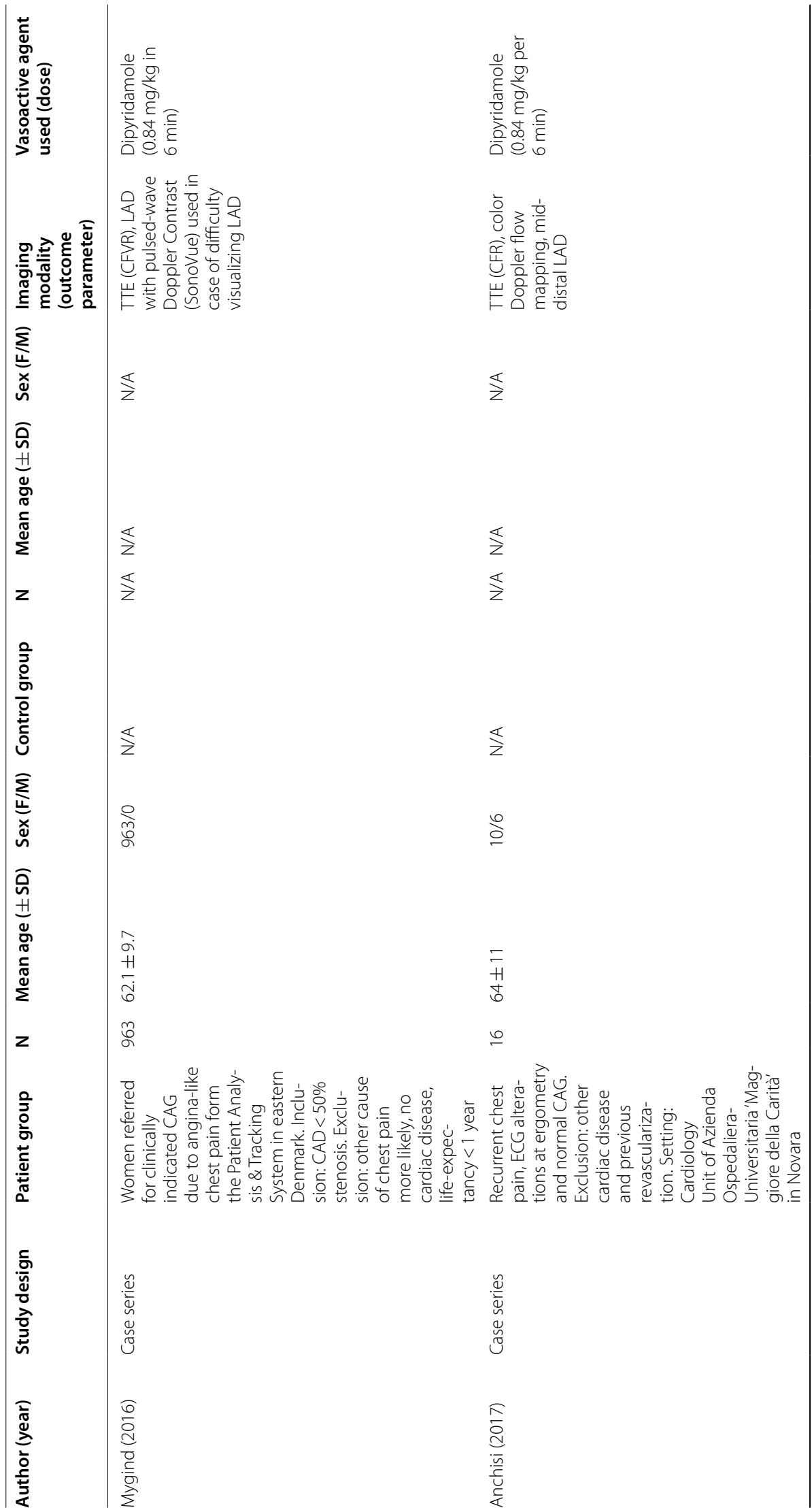




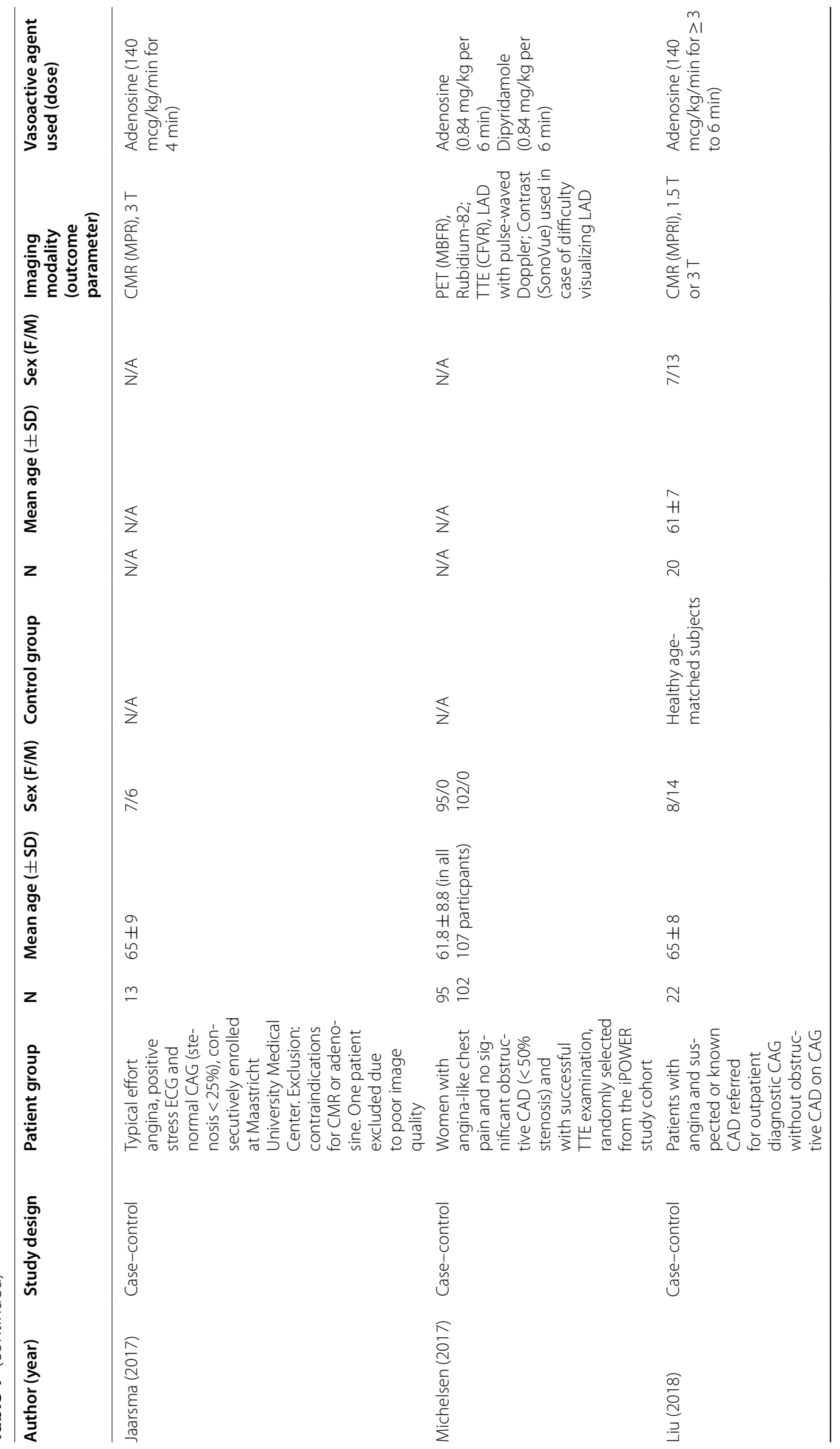




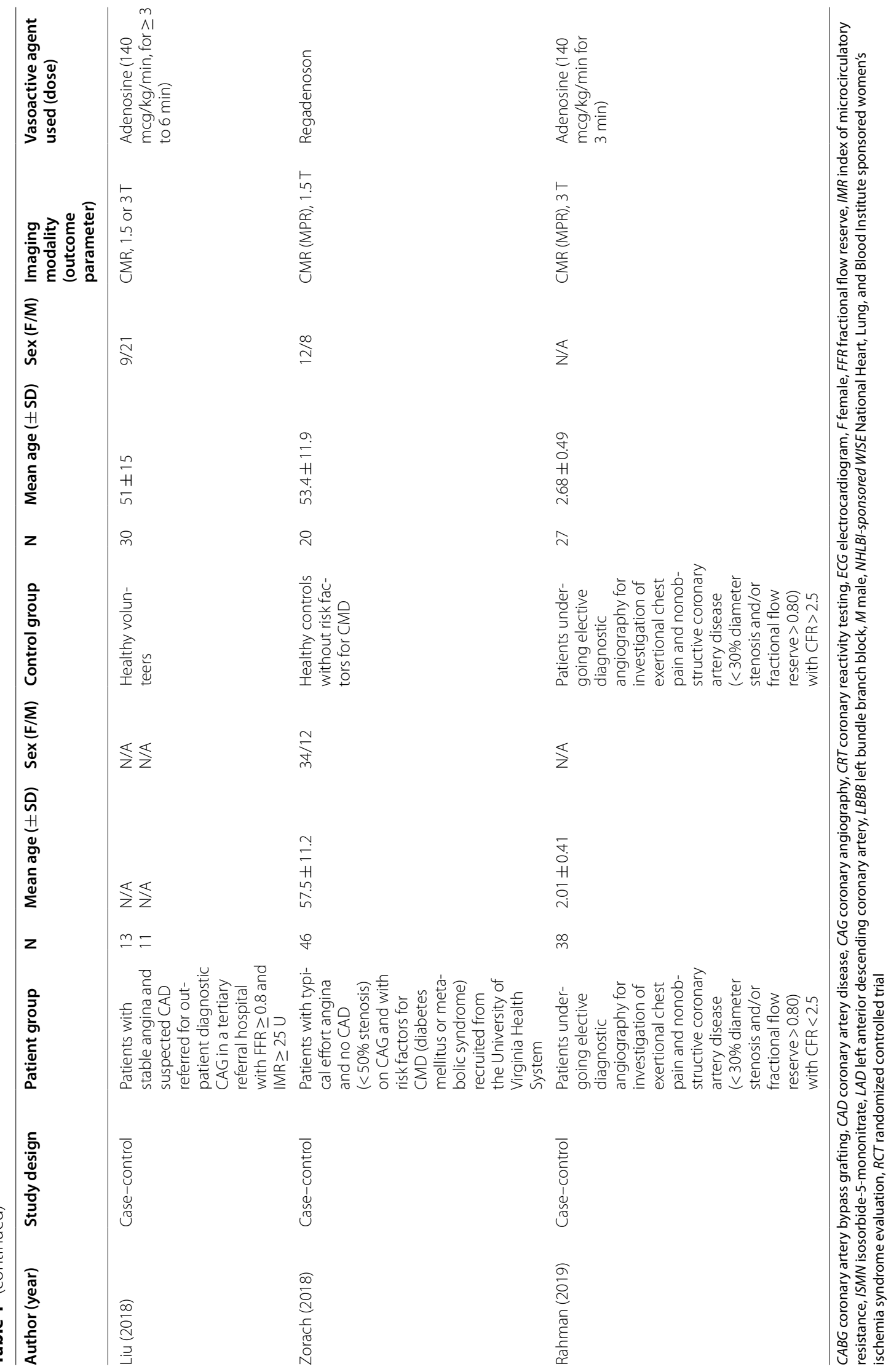




\section{Flow parameters}

Different flow parameters were reported (Table 2). In CMR studies, the myocardial perfusion reserve index (MPRI) was most often reported. Other parameters reported were myocardial perfusion reserve (MPR) and CFR. MPR is defined as the ratio between the relative upslope of myocardial signal intensity (obtained with the use of gadolinium as contrast agent) during stress and rest. In contrast to MPR, the MPRI is corrected for left ventricular contrast signal intensity, allowing for a reduction in signal differences within the image and intra-individual level differences in signal intensity due to heart rate and blood pressure [6, 23, 24]. As such, MPRI is often the preferred outcome measure as it seems to be more accurate in quantifying coronary microvascular blood flow. In one study, CMR-derived CFR results were presented [25]. CFR was calculated and measured in the exact same way as the MPR and can therefore be considered as a synonym of MPR.

In PET studies microvascular function was usually quantified with CFR. Other outcome parameters were MPR or myocardial flow reserve (MFR). MPR and MFR were calculated based on the same methods and measurements as CFR and could therefore be used interchangeably. CFR was defined as the ratio between hyperemic and resting myocardial blood flow (MBF) $[26,27]$ which was expressed in $\mathrm{ml} / \mathrm{min} / \mathrm{g}$ [28]. CFR was often corrected for rate pressure product (RPP), defined as heart rate multiplied by systolic blood pressure and represents cardiac metabolic demand. This correction is recommended as it reduces variability in outcomes due to person-level differences in systolic blood pressure and heart rate $[2,27]$.

In TTE studies CFR was used. Similar to PET and CMR, a variety of equivalent terms were reported, namely CFR, coronary blood flow (CBF) and coronary flow velocity reserve (CFVR). CFR, CBF and CFVR were all defined as the ratio of peak stress and rest coronary blood flow velocities (CBFV), usually obtained by spectral Doppler measurements.

\section{CMR imaging}

CMR was used to diagnose CMD in 15 of the 37 included studies (Additional file 3: Table S2) [6, 15, 23, 25, 29-39]. CMR results are mostly expressed as the MPRI $(n=11)$. The other outcome parameters mentioned were MPR and CFR $(n=5)$. One study assessed MPRI as well as MPR [29]. Patient groups were globally comparable as all studies included patients with AP without CAD on CAG. Absolute mean transmural mean MPRI values in patient groups ranged from $1.47 \pm 0.36$ to $2.01 \pm 0.41$. In controls, mean MPRI ranged from $1.50 \pm 0.47$ to $2.68 \pm 0.49$. The results of CMR studies with MPRI as outcome parameter in patients and controls are summarized in Fig. 2a.

\section{PET imaging}

A total of 13 studies used PET to quantify coronary microvascular function (Additional file 4: Table S3) [16, 35, 40-50]. PET studies reporting mean CFR as outcome measure, mean CFR ranged from $1.39 \pm 0.31$ to $2.85 \pm 1.35$ in patient groups. In the control group, mean CFR ranged from $2.68 \pm 0.83$ to $4.32 \pm 1.78$. The results of PET studies with CFR as outcome parameter in patients and controls are summarized in Fig. $2 \mathrm{~b}$.

\section{TTE imaging}

In 11 studies CMD was assessed by TTE (Additional file 5: Table S4) $[16,51-60]$. All studies calculated CFR as the ratio of basal and hyperemic diastolic flow velocity measured in the left anterior descending coronary artery (LAD). In the included TTE studies, patient groups were comparable with regard to inclusion of patients with AP and no or nonobstructive CAD on CAG (Table 1). Two RCTs were included, mentioning CFR at baseline. A mean CFR of $1.69 \pm 0.40$ to $2.40 \pm 0.40$ was found in patients with angina and no CAD on CAG, whereas healthy control subjects show a higher mean CFR of $2.65 \pm 0.65$ to $3.31 \pm 1.10$. An overview of the CFR outcomes of TTE studies in patients and controls is presented in Fig. 2c.

\section{Sex differences}

Only one of the included studies compared outcomes between men and women. Sestito et al. [56] determined CBF (defined as the ratio of diastolic CBF velocity at peak stress and rest) using TTE in 71 patients diagnosed with CMD (48 women, 67.6\%). No significant difference in CBF was found between men and women (CBF $2.09 \pm 0.60$ and $2.03 \pm 0.50$, respectively). Furthermore, the proportion of women as compared to men in the patient groups was much larger $(89 \%)$ as compared with the control population (33\%).

\section{Discussion}

We provided an overview of currently used non-invasive imaging techniques and corresponding reference values for CMD in patients with AP and no or nonobstructive $\mathrm{CAD}$ as well as healthy subjects. We found quite some differences between reported non-invasive imaging parameters to assess CMD, which we have summarized in Fig. 2. These differences reflect the large heterogeneity between the studied population as well as the rapidly developing imaging techniques and protocols per imaging technique, which result in a variety of different study protocols. Due to the heterogeneity between the included 
studies we were unable to perform a formal meta-analysis and provide clear clinically applicable cut-off values to diagnose CMD.

MPRI was found to correlate well with invasive measurements obtained with CRT, such as index of microcirculatory resistance and CFR $[15,23]$. Therefore, MPRI could potentially serve as a non-invasive alternative to CRT. Current literature proposes two different cut-off values, namely 1.40 and $1.84[6,15]$, corresponding with the results found in this review. However, the results of this review suggest a grey area of MPRI values, as some overlap is seen between MPRI in patients and healthy controls. Stress MBF values can aid in differentiating CMD from normal coronary microvascular function. Liu et al. [15] have shown that a decreased stress MBF (i.e. less than $2.30 \mathrm{ml} / \mathrm{min} / \mathrm{g}$ ) is suggestive of CMD in patients with inconclusive MPRI values. Furthermore, some CMR studies now investigate the clinical applicability of quantitative myocardial tissue characterization with rest and stress T1 mapping as an alternative [29, 33]. Ischemic myocardial tissue can be differentiated from healthy tissue based on distinct properties at T1 mapping during rest and stress conditions, without the use of contrast agents. However, the diagnostic value of $\mathrm{T} 1$ mapping in diagnosing CMD still needs extensive validation [29].

Currently, PET is the most frequently applied and validated non-invasive imaging technique in quantifying microvascular blood flow. PET is considered the golden standard of non-invasive diagnosis of CMD, although discordance between invasive fractional flow reserve (FFR) and non-invasive CFR is reported in up to $30 \%$ of cases [16, 26, 27, 61]. CMD is generally diagnosed with a CFR less than 2.0 if corrected for RPP or less than 2.5 if uncorrected [28, 35, 45, 47]. However, no evidencebased cut-off values for CFR in PET are available yet. Similarly, no cut-off values for CFR in TTE have yet been determined and generally a cut-off value of less than 2.0 for the diagnosis of CMD is applied [18, 58, 62-65]. The study of Hildick-Smith et al. showed CFR with use of adenosine stress TTE to be well above this applied cut-off value, i.e. a mean CFR 3.7 in healthy controls and 5.9 in athletes [66]. However these study population comprised men of 27 years of age and could therefore not be directly used as reference value for the, mainly older and female, population of interest at risk for CMD. TTE assessment of CFR with Doppler echocardiography has been validated against intracoronary Doppler measurements and outcomes correlate well $[2,5,60,67]$.

\section{Causes of heterogeneity in measured outcome parameters Patient groups}

The heterogeneity in outcomes observed in this systematic review is most likely the result of differences in inclusion criteria applied across several studies and differences in the use of imaging techniques. Although most studies investigated patients with typical AP and no or nonobstructive CAD during diagnostic CAG, the setting in which participants were recruited was not reported clearly. Furthermore, the definition of no or nonobstructive CAD and the control population was often unclear and, if documented, heterogeneous among the included studies (Additional file 6: Table S5). Therefore, a more homogeneous definition could not be applied in the search method. Hence, we suggest the use and documentation of standardized criteria as reported by COVADIS [12].

\section{Methodological differences}

Unclarity of the used reference standard, as reflected by the risk of bias assessment (Additional file 2: Table S1), may have introduced significant bias. Moreover, it was often unclear whether researchers were blinded to the

Table 2 Overview of outcome parameters considered in this systematic review

\begin{tabular}{|c|c|c|}
\hline Imaging method & Parameters & Definition \\
\hline \multirow[t]{3}{*}{ Cardiac magnetic resonance imaging (CMR) } & Myocardial perfusion reserve index (MPRI) & $M B F_{\text {stress }} / M F_{\text {rest }}{ }^{*} L V$ contrast signal intensity \\
\hline & Myocardial perfusion reserve (MPR) & $\mathrm{MBF}_{\text {stress }} / \mathrm{MBF}_{\text {rest }}$ \\
\hline & $\begin{array}{l}\text { Coronary flow reserve (corrected for rate pressure } \\
\text { product) (CFR (corrected for RPP)) }\end{array}$ & $\mathrm{MBF}_{\text {stress }} / \mathrm{MBF}_{\text {rest }} *(\mathrm{HR} * \mathrm{SBP} / 10.000)$ \\
\hline \multirow[t]{3}{*}{ Positron emmission tomography (PET) } & $\begin{array}{l}\text { Coronary flow reserve (corrected for rate pressure } \\
\text { product) (CFR (corrected for RPP)) }\end{array}$ & $\mathrm{MBF}_{\text {stress }} / \mathrm{MBF}_{\text {rest }} *\left(H R^{*} \mathrm{SBP} / 10.000\right)$ \\
\hline & Myocardial perfusion reserve (MPR) & $\mathrm{MBF}_{\text {stress }} / \mathrm{MBF}_{\text {rest }}$ \\
\hline & Myocardial flow reserve (MFR) & $\mathrm{MBF}_{\text {stress }} / \mathrm{MBF}_{\text {rest }}$ \\
\hline \multirow[t]{3}{*}{ Transthoracic echocardiography (TTE) } & Coronary flow reserve (CFR) & $\mathrm{MBF}_{\text {stress }} / \mathrm{MBF}_{\text {rest }}$ \\
\hline & Coronary flow velocity reserve (CFVR) & $\mathrm{MBF}_{\text {stress }} / \mathrm{MBF}_{\text {rest }}$ \\
\hline & Coronary blood flow (CBF) & $M B F_{\text {stress }} / M F_{\text {rest }}$ \\
\hline
\end{tabular}

$H R$ heart rate, $L V$ left ventricular, $M B F_{\text {rest }}$ myocardial blood flow in resting conditions, $M B F_{\text {stress }}$ myocardial blood flow during hyperemic circumstances, $S B P$ systolic blood pressure 


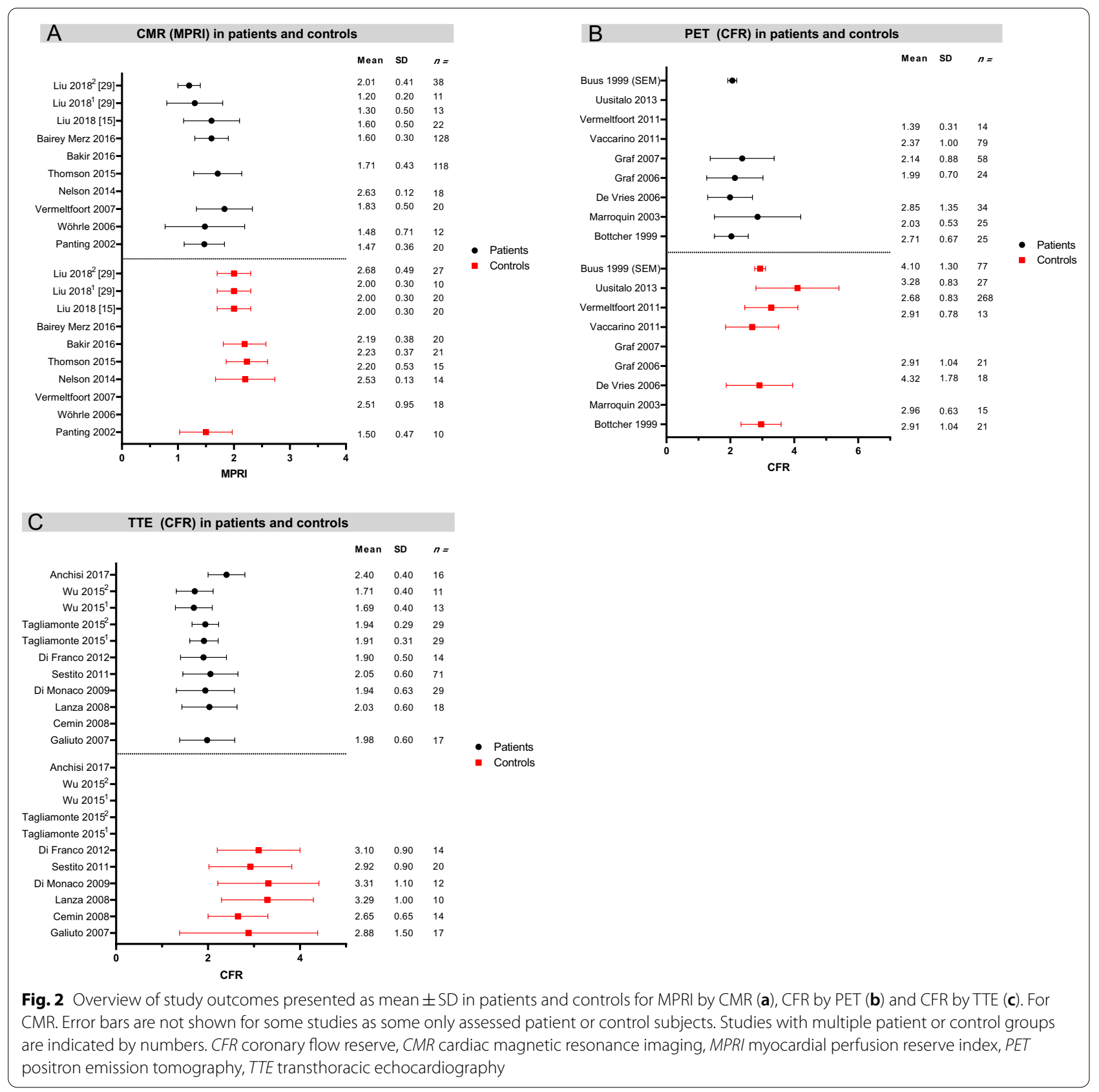

reference standard when interpreting results from the index test.

Furthermore, measurement of MPRI in CMR might contribute to the inconsistent results observed in this systematic review. MPRI can be measured transmural, but also subendo- or epicardial. Several studies show subendocardial MPRI to be decreased more often than epicardial MPRI in CMD patients [34, 39, 64, 68], which might indicate subendocardial MPRI to be more valuable in diagnosing CMD as compared with epicardial or transmural MPRI. Unfortunately, in this systematic review only transmural MPRI values were included.

Regarding PET, correction for RPP is not standard which results in decreased comparability of outcomes. Moreover, the use of different radioactive tracers (15O-water, 13N-ammonia and Rubidium-82) could result in varying outcomes due to differences in characteristics and processing of images [14, 27, 28]. The use of a specific radiotracer might require a specific cut-off value to diagnose CMD [14]. Similar concerns apply to 
the use of various vasoactive agents to achieve hyperemia in stress perfusion imaging. Adenosine and dipyridamole are most commonly administered to achieve hyperemia. However, adenosine seems to be superior to dipyridamole with regard to attaining maximal hyperemia and their effects are not identical. Therefore the use of the different types and doses of vasoactive agent could have contributed to the differences found in the outcome parameters $[27,69,70]$.

Lastly, this systematic review highlights the discordance in nomenclature and reporting of outcomes. Standardization of outcome parameters reported could increase comparability of studies assessing reference values for the diagnosis of CMD.

\section{Sex differences}

In the present analysis women were highly represented in the patient groups $(89 \%)$ compared to control groups (33\%). Therefore, sex differences could contribute to discrepancies between studies resulting in decreased comparability between CFR and MPRI measurements in patient and control groups. Kobayashi et al. [17] measured coronary vascular diameter with quantitative CAG and intravascular ultrasound in patients with $\mathrm{AP}$ and nonobstructive CAD and found a smaller vascular diameter in women. Furthermore, they showed a significantly higher resting CBF in women. The latter is consistent with findings by Opstal et al. [71] and Chareonthaitawee et al. [72] who studied coronary blood flow in healthy subjects with $13 \mathrm{~N}$-ammonia PET $(n=206)$ and 15O-water PET $(n=169)$, respectively. These findings suggest sex differences in flow parameters. High resting myocardial flow volumes could decrease CFR (in PET and TTE) or MPRI (in CMR) in women compared to men as flow parameters are determined as the ratio of stress and rest perfusion. Although sex differences in resting MBF and CFR have been observed in invasive CRT $[3,17,73]$, only one of the included studies included assessed sex differences regarding CBF and reported no significant sex differences [56]. These findings are consistent with another study comparing non-invasive CFR between men and women using PET [74]. Therefore, further research is needed to establish whether or not sexspecific cut-off values are required for the non-invasive diagnosis of CMD.

\section{Recommendations for future research}

The studies included in this review show heterogeneity in study methodology and outcome. This contributes to the discrepancies in outcomes between studies and to the lack of consensus regarding definition and cutoff values for CMD in non-invasive imaging modalities. We emphasize the need for large validation studies and suggest standardization of outcome parameters to reduce heterogeneity and increase comparability of studies. This is needed to provide clinically applicable, possibly sexspecific, reference values for the diagnosis of CMD in the future.

Furthermore, during this systematic review, we found several other imaging modalities that are studied for their potential to diagnose CMD, such as myocardial contrast echocardiography (MCE) $[63,75,76]$, CT-perfusion [77] and absolute quantification of myocardial perfusion by CMR [78]. Even though, current evidence is still limited so the clinical significance and applicability in regular care of these modalities in CMD diagnosis remains unclear, current research shows promising results. For example, Bechsgaard et al. [77] studied CT myocardial perfusion in women with angina and no obstructive CAD, (defined as $<50 \%$ stenosis), in comparison with female controls. They showed CT-perfusion is able to identify decreased global myocardial perfusion and impaired increase of myocardial blood flow during adenosine provocation in women with angina and non obstructive CAD as compared with the control group. The use of CT-perfusion in addition to the commonly performed CCTA could in the future play an important role in the evaluation of CMD early in the evaluation of patients with angina.

\section{Study limitations}

The number of studies investigating non-invasive imaging techniques to diagnose CMD is limited. As such, the results of this systematic review are based on limited data. Hence, only an indication of reference and cut-off values could be provided. Furthermore, a formal metaanalysis could not be performed due to heterogeneity of included studies. In addition, the risk of selection bias in the included studies was high. Also, the heterogeneity in the definition of non obstructive CAD might also have impacted the results as the included studies comprise patients with both completely normal or non obstructed coronaries. Unfortunately, as the definition of nonobstructive CAD was unclear or heterogeneous, it was not possible to separately analyse outcomes for patients with normal coronaries as compared to nonobstructive $\mathrm{CAD}$. These analyses would have been of additive value as in patients with nonobstructive CAD there might still be epicardial stenosis that could impact myocardial blood flow. These limitations emphasize the importance of standardization of imaging protocols and analyses, patient selection and reporting of outcome measurements to obtain reliable and clinically relevant cut-off values for CMD. 


\section{Conclusions}

This systematic review provided an overview of currently used parameters and cut-off values for CMD in patients with AP and no or nonobstructive CAD as well as healthy subjects. However, no definite cut-off values could be determined as no meta-analysis could be performed due to heterogeneity of studies investigating non-invasive imaging techniques in CMD.

\begin{abstract}
Abbreviations
AP: Angina pectoris; CAD: Coronary artery disease; CAG: Coronary aniography; CFR: Coronary flow reserve; CMD: Coronary microvascular dysfunction; CMR: Cardiac magnetic resonance imaging; COVADIS: Coronary Vasomotor Disorders International Study Group; CRT: Coronary reactivity testing; MBF: Myocardial blood flow; MPR: Myocardial perfusion reserve; MPRI: Myocardial perfusion reserve index; PET: Positron emission tomography; TTE: Transthoracic echocardiography.
\end{abstract}

\section{Supplementary Information}

The online version contains supplementary material available at https://doi. org/10.1186/s12880-020-00535-7.

Additional file 1. Search Strategy.

Additional file 2: Table S1. Table S2 Risk of bias assessment according to QUADAS-2.

Additional file 3: Table S2. Quantification of coronary microvascular dysfunction in CMR studies.

Additional file 4: Table S3. Quantification of coronary microvascular dysfunction in PET studies. Correction for RPP is indicated by + or - .

Additional file 5: Table S4. Quantification of coronary microvascular dysfunction in TTE studies.

Additional file 6: Table S5. Definition of nonobstructive CAD in included studies.

\section{Acknowledgements}

Not applicable.

\section{Authors' contributions}

FG and RGMK participated in the design of the study, collected the data, performed the statistical analysis and drafted the manuscript. GBV participated in the design of the study and assisted with manuscript preparation. SHB, NCOM, HMDR and TL assisted with manuscript preparation. ALME participated in the design of the study and drafted the manuscript. All authors read and approved the final manuscript.

\section{Funding}

This study was funded by Dutch Heart Foundation (CVON 2017-22 ARGUS). The funding body played no role in the design of the study and collection, analysis, and interpretation of data and in writing the manuscript.

\section{Availability of data and materials}

The datasets used and/or analysed during the current study are available from the corresponding author on reasonable request.

\section{Ethics approval and consent to participate}

Not applicable.

\section{Consent for publication}

Not applicable.

\section{Competing interests}

The authors declare that they have no competing interests.

\section{Author details}

${ }^{1}$ Laboratory of Experimental Cardiology, University Medical Center Utrecht, Utrecht University, Heidelberglaan 100, 3584 CX Utrecht, The Netherlands. ${ }^{2}$ Department of Clinical Chemistry and Hematology, University Medical Center Utrecht, Utrecht University, Utrecht, The Netherlands. ${ }^{3}$ Department of Epidemiology, Julius Center for Health Sciences and Primary Care, University Medical Center Utrecht, Utrecht University, Utrecht, The Netherlands. ${ }^{4}$ Department of Radiology, University Medical Center Utrecht, Utrecht University, Utrecht, The Netherlands.

Received: 17 October 2020 Accepted: 8 December 2020

Published online: 06 January 2021

\section{References}

1. Patel MR, Peterson ED, Dai D, Brennan JM, Redberg RF, Anderson HV, Brindis RG, Douglas PS. Low diagnostic yield of elective coronary angiography. N Engl J Med. 2010;362:886-95. https://doi.org/10.1056/NEJMo a0907272.

2. Chen C, Wei J, AlBadri A, Zarrini P, Bairey Merz C. Coronary microvascular dysfunction-epidemiology, pathogenesis, prognosis, diagnosis, risk factors and therapy. Circ J. 2016;81:3-11. https://doi.org/10.1253/circj. CJ-16-1002.

3. Sara JD, Widmer RJ, Matsuzawa Y, Lennon RJ, Lerman LO, Lerman A. Prevalence of coronary microvascular dysfunction among patients with chest pain and nonobstructive coronary artery disease. JACC Cardiovasc Interv. 2015:8:1445-53. https://doi.org/10.1016/j.jcin.2015.06.017.

4. Camici PG, Crea F. Coronary microvascular dysfunction. N Engl J Med. 2007;356:830-40. https://doi.org/10.1056/NEJMra061889.

5. Dean J, Dela CS, Mehta PK, Merz CNB. Coronary microvascular dysfunction: sex-specific risk, diagnosis, and therapy. Nat Rev Cardiol. 2015;12:406-14. https://doi.org/10.1038/nrcardio.2015.72.

6. Thomson LEJ, Wei J, Agarwal M, Haft-Baradaran A, Shufelt C, Mehta PK, Gill EB, Johnson BD, Kenkre T, Handberg EM, Li D, Sharif B, Berman DS, Petersen JW, Pepine CJ, Merz CNB. Cardiac magnetic resonance myocardial perfusion reserve index is reduced in women with coronary microvascular dysfunction: a national heart, lung, and blood institutesponsored study from the women's ischemia syndrome evaluation. Circ Cardiovasc Imaging. 2015;8:e002481. https://doi.org/10.1161/CIRCIMAGING.114.002481.

7. Sharaf B, Wood T, Shaw L, Johnson BD, Kelsey S, Anderson RD, Pepine CJ, Bairey Merz CN. Adverse outcomes among women presenting with signs and symptoms of ischemia and no obstructive coronary artery disease: Findings from the National Heart, Lung, and Blood Institute-sponsored Women's Ischemia Syndrome Evaluation (WISE) angiographic core lab. Am Heart J. 2013;166:134-41. https://doi.org/10.1016/j.ahj.2013.04.002.

8. Taqueti VR, Shaw LJ, Cook NR, Murthy VL, Shah NR, Foster CR, Hainer J, Blankstein R, Dorbala S, Di Carli MF. Excess cardiovascular risk in women relative to men referred for coronary angiography is associated with severely impaired coronary flow reserve, not obstructive disease. Circulation. 2017;135:566-77. https://doi.org/10.1161/CIRCULATIONAHA.116. 023266.

9. Marinescu MA, Löffler Al, Ouellette M, Smith L, Kramer CM, Bourque JM. Coronary microvascular dysfunction, microvascular angina, and treatment strategies. JACC Cardiovasc Imaging. 2015;8:210-20. https://doi. org/10.1016/j.jcmg.2014.12.008.

10. Murthy VL, Naya M, Taqueti VR, Foster CR, Gaber M, Hainer J, Dorbala S, Blankstein R, Rimoldi O, Camici PG, Di Carli MF. Effects of sex on coronary microvascular dysfunction and cardiac outcomes. Circulation. 2014;129:2518-27. https://doi.org/10.1161/CIRCULATIONAHA.113. 008507.

11. Pepine CJ, Anderson RD, Sharaf BL, Reis SE, Smith KM, Handberg EM, Johnson BD, Sopko G, Bairey Merz CN. Coronary microvascular reactivity to adenosine predicts adverse outcome in women evaluated for suspected ischemia. results from the National Heart, Lung and Blood Institute WISE (Women's Ischemia Syndrome Evaluation) Study. J Am Coll Cardiol. 2010;55:2825-32. https://doi.org/10.1016/j.jacc.2010.01.054.

12. Ong P, Camici PG, Beltrame JF, Crea F, Shimokawa H, Sechtem U, Kaski JC, Bairey Merz CN. International standardization of diagnostic criteria for 
microvascular angina. Int J Cardiol. 2018;250:16-20. https://doi.org/10. 1016/j.ijcard.2017.08.068.

13. Knuuti J, Wijns W, Achenbach S, Agewall S, Barbato E, Bax JJ, Capodanno D, Cuisset T, Deaton C, Dickstein K, Edvardsen T, Escaned J, FunckBrentano C, Gersh BJ, Gilard M, Hasdai D, Hatala R, Mahfoud F, Masip J, Muneretto C, Prescott E, Saraste A, Storey RF, Svitil P, Valgimigli M, Windecker S, Aboyans V, Baigent C, Collet JP, Dean V, Delgado V, Fitzsimons D, Gale CP, Grobbee DE, Halvorsen S, Hindricks G, lung B, Jüni P, Katus HA, Landmesser U, Leclerca C, Lettino M, Lewis BS, Merkely B, Mueller C, Petersen S, Petronio AS, Richter DJ, Roffi M, Shlyakhto E, Simpson IA, Sousa-Uva M, Touyz RM, Benkhedda S, Metzler B, Sujayeva V, Cosyns B, Kusljugic Z, Velchev V, Panayi G, Kala P, Haahr-Pedersen SA, Kabil H, Ainla T, Kaukonen T, Cayla G, Pagava Z, Woehrle J, Kanakakis J, Toth K, Gudnason T, Peace A, Aronson D, Riccio C, Elezi S, Mirrakhimov E, Hansone S, Sarkis A, Babarskiene R, Beissel J, Cassar Maempel AJ, Revenco V, de Grooth GJ, Pejkov H, Juliebø V, Lipiec P, Santos J, Chioncel O, Duplyakov D, Bertelli L, Dikic AD, Studencan M, Bunc M, Alfonso F, Back M, Zellweger M, Addad F, Yildirir A, Sirenko Y, Clapp B. 2019 ESC guidelines for the diagnosis and management of chronic coronary syndromes. Eur Heart J. 2020;41:40777. https://doi.org/10.1093/eurheartj/ehz425.

14. Schindler TH, Dilsizian V. Coronary microvascular dysfunction: clinical considerations and noninvasive diagnosis. JACC Cardiovasc Imaging. 2020;13:140-55. https://doi.org/10.1016/j.jcmg.2018.11.036.

15. Liu A, Wijesurendra RS, Liu JM, Forfar JC, Channon KM, Jerosch-Herold M, Piechnik SK, Neubauer S, Kharbanda RK, Ferreira VM. Diagnosis of microvascular angina using cardiac magnetic resonance. J Am Coll Cardiol. 2018;71:969-79. https://doi.org/10.1016/j.jacc.2017.12.046.

16. Michelsen MM, Mygind ND, Pena A, Olsen RH, Christensen TE, Ghotbi AA, Hasbak P, Kjaer A, Gustafsson I, Hansen PR, Hansen HS, Høst N, Kastrup J, Prescott E. Transthoracic Doppler echocardiography compared with positron emission tomography for assessment of coronary microvascular dysfunction: The iPOWER study. Int J Cardiol. 2017;228:435-43. https:// doi.org/10.1016/j.jijcard.2016.11.004.

17. Kobayashi Y, Fearon WF, Honda Y, Tanaka S, Pargaonkar V, Fitzgerald PJ, Lee DP, Stefanick M, Yeung AC, Tremmel JA. Effect of sex differences on invasive measures of coronary microvascular dysfunction in patients with angina in the absence of obstructive coronary artery disease. JACC Cardiovasc Interv. 2015;8:1433-41. https://doi.org/10.1016/j.jcin.2015.03. 045.

18. Nagel E, Klein C, Paetsch I, Hettwer S, Schnackenburg B, Wegscheider K, Fleck E. Magnetic resonance perfusion measurements for the noninvasive detection of coronary artery disease. Circulation. 2003;108:432-7. https://doi.org/10.1161/01.CIR.0000080915.35024.A9.

19. Anderson RD, Petersen JW, Mehta PK, Wei J, Johnson BD, Handberg EM, Kar S, Samuels B, Azarbal B, Kothawade K, Kelsey SF, Sharaf B, Shaw LJ, Sopko G, Bairey Merz CN, Pepine CJ. Prevalence of coronary endothelial and microvascular dysfunction in women with symptoms of ischemia and no obstructive coronary artery disease is confirmed by a new cohort: The NHLBI-sponsored women's ischemia syndrome evaluation-coronary vascular dysfunc. J Interv Cardiol. 2019. https://doi.org/10.1155/2019/ 7169275.

20. AlBadri A, Leong D, Bairey Merz CN, Wei J, Handberg EM, Shufelt CL, Mehta PK, Nelson MD, Thomson LE, Berman DS, Shaw LJ, Cook-Wiens G, Pepine CJ. Typical angina is associated with greater coronary endothelial dysfunction but not abnormal vasodilatory reserve. Clin Cardiol. 2017:40:886-91. https://doi.org/10.1002/clc.22740.

21. Mathew RC, Bourque JM, Salerno M, Kramer CM. Cardiovascular imaging techniques to assess microvascular dysfunction. JACC Cardiovasc Imaging. 2020;13:1577-90. https://doi.org/10.1016/j.jcmg.2019.09.006.

22. Whiting PF, Rutjes AWS, Westwood ME, Mallett S, Deeks JJ, Reitsma JB, Leeflang MMG, Sterne JAC, Bossuyt PMM. Quadas-2: a revised tool for the quality assessment of diagnostic accuracy studies. Ann Intern Med. 2011;155:529-36. https://doi.org/10.7326/0003-4819-155-8-20111 0180-00009.

23. Wöhrle J, Nusser T, Merkle N, Kestler HA, Grebe OC, Marx N, Höher M, Kochs M, Hombach V. Myocardial perfusion reserve in cardiovascular magnetic resonance: correlation to coronary microvascular dysfunction. J Cardiovasc Magn Reson. 2006;8:781-7. https://doi.org/10.1080/10976 640600737649 .
24. Löffler Al, Bourque JM. Coronary microvascular dysfunction, microvascular angina, and management. Curr Cardiol Rep. 2016;18:1-7. https://doi. org/10.1007/s11886-015-0682-9.

25. Karamitsos TD, Arnold JR, Pegg TJ, Francis JM, Birks J, Jerosch-Herold M, Neubauer S, Selvanayagam JB. Patients with syndrome X have normal transmural myocardial perfusion and oxygenation: a 3-T cardiovascular magnetic resonance imaging study. Circ Cardiovasc Imaging. 2012;5:194200. https://doi.org/10.1161/CIRCIMAGING.111.969667.

26. Pelletier-Galarneau M, Martineau P, El Fakhri G. Quantification of PET myocardial blood flow. Curr Cardiol Rep. 2019;21:11. https://doi.org/10. 1007/s11886-019-1096-x.

27. Feher A, Sinusas AJ. Quantitative assessment of coronary microvascular function: dynamic single-photon emission computed tomography, positron emission tomography, ultrasound, computed tomography, and magnetic resonance imaging. Circ Cardiovasc Imaging. 2017;10:e006427. https://doi.org/10.1161/CIRCIMAGING.117.006427.

28. Camici PG, D'Amati G, Rimoldi O. Coronary microvascular dysfunction: mechanisms and functional assessment. Nat Rev Cardiol. 2015;12:48-62. https://doi.org/10.1038/nrcardio.2014.160Introduction.

29. Liu A, Wijesurendra RS, Liu JM, Greiser A, Jerosch-Herold M, Forfar JC, Channon KM, Piechnik SK, Neubauer S, Kharbanda RK, Ferreira VM. Gadolinium-free cardiac MR stress T1-mapping to distinguish epicardial from microvascular coronary disease. J Am Coll Cardiol. 2018;71:957-68. https://doi.org/10.1016/j.jacc.2017.11.071.

30. Rahman H, Ryan M, Lumley M, Modi B, Mcconkey H, Ellis H, Scannell C, Clapp B, Marber M, Webb A, Chiribiri A, Perera D. Coronary microvascular dysfunction is associated with myocardial ischemia and abnormal coronary perfusion during exercise. Circulation. 2019;140:1805-16. https://doi. org/10.1161/CIRCULATIONAHA.119.041595.

31. Jaarsma C, Vink H, van Haare J, Bekkers SCAM, van Rooijen BD, Backes WH, Wildberger JE, Crijns HJ, van Teeffelen J, Schalla S. Non-invasive assessment of microvascular dysfunction in patients with microvascular angina. Int J Cardiol. 2017;248:433-9. https://doi.org/10.1016/j.ijcard.2017.05.010.

32. Mehta PK, Goykhman P, Thomson LEJ, Shufelt C, Wei J, Yang Y, Gill E, Minissian M, Shaw LJ, Slomka PJ, Slivka M, Berman DS, Bairey Merz CN. Ranolazine improves angina in women with evidence of myocardial ischemia but no obstructive coronary artery disease. JACC CardiovasC Imaging. 2011;4:514-22. https://doi.org/10.1016/j.jcmg.2011.03.007.

33. Zorach B, Shaw PW, Bourque J, Kuruvilla S, Balfour PC, Yang Y, Mathew R, Pan J, Gonzalez JA, Taylor AM, Meyer CH, Epstein FH, Kramer CM, Salerno M. Quantitative cardiovascular magnetic resonance perfusion imaging identifies reduced flow reserve in microvascular coronary artery disease. J Cardiovasc Magn Reson. 2018;20:1-8. https://doi.org/10.1186/ s12968-018-0435-1.

34. Panting JR, Gatehouse PD, Yang GZ, Grothues F, Firmin DN, Collins P, Pennell DJ. Abnormal subendocardial perfusion in cardiac syndrome $X$ detected by cardiovascular magnetic resonance imaging. N Engl I Med. 2002;346:1948-53. https://doi.org/10.1056/NEJMoa012369.

35. Pärkkä JP, Niemi P, Saraste A, Koskenvuo JW, Komu M, Oikonen V, Toikka JO, Kiviniemi TO, Knuuti J, Sakuma H, Hartiala JJ. Comparison of MRI and positron emission tomography for measuring myocardial perfusion reserve in healthy humans. Magn Reson Med. 2006;55:772-9. https://doi. org/10.1002/mrm.20833.

36. Vermeltfoort I, Bondarenko O, Raijmakers P, Odekerken D, Kuijper A, Zwijnenburg A, Van der Vis-Melsen M, Twisk J, Beek M, Teule G, Van Rossum A. Is subendocardial ischaemia present in patients with chest pain and normal coronary angiograms? A cardiovascular MR study [5]. Eur Heart J. 2007;28:2687-8. https://doi.org/10.1093/eurheartj/ehm381.

37. Nelson MD, Szczepaniak LS, Wei J, Haftabaradaren A, Bharadwaj M, Sharif B, Mehta P, Zhang X, Thomson LE, Berman DS, Li D, Merz CNB. Diastolic dysfunction in women with signs and symptoms of ischemia in the absence of obstructive coronary artery disease: a hypothesis-generating study. Circ Cardiovasc Imaging. 2014;7:510-6. https://doi.org/10.1161/ CIRCIMAGING.114.001714.

38. Merz CNB, Handberg EM, Shufelt CL, Mehta PK, Minissian MB, Wei J, Thomson LEJ, Berman DS, Shaw LJ, Petersen JW, Brown GH, Anderson RD, Shuster JJ, Cook-Wiens G, Rogatko A, Pepine CJ. A randomized, placebocontrolled trial of late Na current inhibition (ranolazine) in coronary microvascular dysfunction (CMD): impact on angina and myocardial perfusion reserve. Eur Heart J. 2016;37:1504-13. https://doi.org/10.1093/ eurheartj/ehv647. 
39. Bakir M, Wei J, Nelson MD, Mehta PK, Haftbaradaran A, Jones E, Gill E, Sharif B, Slomka PJ, Li D, Shufelt CL, Minissian M, Berman DS, Noel Bairey Merz C, Thomson LEJ. Cardiac magnetic resonance imaging for myocardial perfusion and diastolic function-reference control values for women. Cardiovasc Diagn Ther. 2016;6:78-86. https://doi.org/10.3978/j.issn.22233652.2015.09.03.

40. Uusitalo V, Saraste A, Kajander S, Luotolahti M, Wendelin-Saarenhovi M, Sundell J, Raitakari O, Knuuti J. The association between coronary flow reserve and development of coronary calcifications: a follow-up study for 11 years in healthy young men. Eur Heart J Cardiovasc Imaging. 2013;14:812-8. https://doi.org/10.1093/ehjci/jes301.

41. Buus NH, Bøttcher M, Bøtker HE, Sørensen KE, Nielsen TT, Mulvany MJ. Reduced vasodilator capacity in syndrome $X$ related to structure and function of resistance arteries. Am J Cardiol. 1999. https://doi.org/10. 1016/S0002-9149(98)00815-7.

42. Bøttcher M, Bøtker HE, Sonne H, Nielsen TT, Czernin J. Endotheliumdependent and -independent perfusion reserve and the effect of L-arginine on myocardial perfusion in patients with syndrome X. Circulation. 1999;99:1795-801. https://doi.org/10.1161/01.CIR.99.14.1795.

43. Meeder JG, Blanksma PK, Van Der Wall EE, Willemsen ATM, Pruim J, Anthonio RL, De Jong RM, Vaalburg W, Lie KI. Coronary vasomotion in patients with syndrome X: evaluation with positron emission tomography and parametric myocardial perfusion imaging. Eur J Nucl Med. 1997;24:530-7. https://doi.org/10.1007/BF01267685.

44. Marroquin OC, Holubkov R, Edmundowicz D, Rickens C, Pohost G, Buchthal S, Pepine CJ, Sopko G, Sembrat RC, Meltzer CC, Reis SE. Heterogeneity of microvascular dysfunction in women with chest pain not attributable to coronary artery disease: Implications for clinical practice. Am Heart J. 2003;145:628-35. https://doi.org/10.1067/mhj.2003.95.

45. Graf S, Khorsand A, Gwechenberger M, Schütz M, Kletter K, Sochor H, Dudczak R, Maurer G, Pirich C, Porenta G, Zehetgruber M. Myocardial perfusion in patients with typical chest pain and normal angiogram. Eur J Clin Invest. 2006;36:326-32. https://doi.org/10.1111/j.1365-2362.2006. 01635.x.

46. De Vries J, Dejongste MJL, Jessurun GAJ, Jager PL, Staal MJ, Slart RHJA, Slart HJA. Myocardial perfusion quantification in patients suspected of cardiac syndrome $X$ with positive and negative exercise testing: A [13 N] ammonia positron emission tomography study. Philadelphia: Lippincott Williams \& Wilkins; 2006

47. Graf S, Khorsand A, Gwechenberger M, Novotny C, Kletter K, Sochor H, Pirich C, Maurer G, Porenta G, Zehetgruber M. Typical chest pain and normal coronary angiogram: cardiac risk factor analysis versus PET for detection of microvascular disease. J Nucl Med. 2007;48:175-81.

48. Scholtens AM, Tio RA, Willemsen A, Dierckx RAJO, Boersma HH, Zeebregts CJ, Glaudemans AWJM, Slart RHJA. Myocardial perfusion reserve compared with peripheral perfusion reserve: a [13N]ammonia PET study. J Nucl Cardiol. 2011;18:238-46. https://doi.org/10.1007/s12350-011-9339-2.

49. Vaccarino V, Khan D, Votaw J, Faber T, Veledar E, Jones DP, Goldberg J, Raggi P, Quyyumi AA, Bremner JD. Inflammation is related to coronary flow reserve detected by positron emission tomography in asymptomatic male twins. J Am Coll Cardiol. 2011;57:1271-9. https://doi.org/10. 1016/j.jacc.2010.09.074.

50. Vermeltfoort IA, Raijmakers PG, Lubberink M, Germans T, Van Rossum AC, Lammertsma AA, Knaapen P. Feasibility of subendocardial and subepicardial myocardial perfusion measurements in healthy normals with 150-labeled water and positron emission tomography. J Nucl Cardiol. 2011;18:650-6. https://doi.org/10.1007/s12350-011-9375-y.

51. Galiuto L, Sestito A, Barchetta S, Sgueglia GA, Infusino F, La Rosa C, Lanza $G$, Crea F. Noninvasive evaluation of flow reserve in the left anterior descending coronary artery in patients with cardiac syndrome X. Am J Cardiol. 2007;99:1378-83. https://doi.org/10.1016/j.amjcard.2006.12.070.

52. Mygind ND, Michelsen MM, Pena A, Qayyum AA, Frestad D, Christensen TE, Ghotbi AA, Dose N, Faber R, Vejlstrup N, Hasbak P, Kjaer A, Prescott E, Kastrup J. Coronary microvascular function and myocardial fibrosis in women with angina pectoris and no obstructive coronary artery disease: the iPOWER study. J Cardiovasc Magn Reson. 2016;18:1-12. https://doi. org/10.1186/s12968-016-0295-5.

53. Cemin R, Erlicher A, Fattor B, Pitscheider W, Cevese A. Reduced coronary flow reserve and parasympathetic dysfunction in patients with cardiovascular syndrome X. Coron Artery Dis. 2008;19:1-7. https://doi.org/10.1097/ MCA.0b013e3282f18e8d.
54. Lanza GA, Buffon A, Sestito A, Natale L, Sgueglia GA, Galiuto L, Infusino F, Mariani L, Centola A, Crea F. Relation between stress-induced myocardial perfusion defects on cardiovascular magnetic resonance and coronary microvascular dysfunction in patients with cardiac syndrome X. J Am Coll Cardiol. 2008;51:466-72. https://doi.org/10.1016/j.jacc.2007.08.060.

55. Di MA, Bruno I, Sestito A, Lamendola P, Barone L, Bagnato A, Nerla R, Pisanello C, Giordano A, Lanza GA, Crea F. Cardiac adrenergic nerve function and microvascular dysfunction in patients with cardiac syndrome $X$. Heart. 2009;95:550-4. https://doi.org/10.1136/hrt.2008.156851.

56. Sestito A, Lanza GA, Di Monaco A, Lamendola P, Careri G, Tarzia P, Pinnacchio G, Battipaglia I, Crea F. Relation between cardiovascular risk factors and coronary microvascular dysfunction in cardiac syndrome X. J Cardiovasc Med. 2011;12:322-7. https://doi.org/10.2459/JCM.0b013 e3283406479.

57. Di Franco A, Lanza GA, Di Monaco A, Sestito A, Lamendola P, Nerla R, Tarzia P, Virdis D, Vollono C, Valeriani M, Crea F. Coronary microvascular function and cortical pain processing in patients with silent positive exercise testing and normal coronary arteries. Am J Cardiol. 2012;109:1705-10. https://doi.org/10.1016/j.amjcard.2012.02.012.

58. Tagliamonte E, Rigo F, Cirillo T, Astarita C, Quaranta G, Marinelli U, Caruso A, Romano C, Capuano N. Effects of ranolazine on noninvasive coronary flow reserve in patients with myocardial ischemia but without obstructive coronary artery disease. Echocardiography. 2015;32:516-21. https:// doi.org/10.1111/echo.12674.

59. Wu M, Villano A, Russo G, Di Franco A, Stazi A, Lauria C, Sestito A, Lanza GA, Crea F. Poor tolerance and limited effects of isosorbide-5-mononitrate in microvascular angina. Cardiology. 2015;130:201-6. https://doi. org/10.1159/000370027.

60. Anchisi C, Marti G, Bellacosa I, Mary D, Vacca G, Marino P, Grossini E. Coronary flow reserve/diastolic function relationship in anginasuffering patients with normal coronary angiography. J Cardiovasc Med. 2017;18:325-31. https://doi.org/10.2459/JCM.0000000000000344.

61. Slomka P, Berman DS, Alexanderson E, Germano G. The role of PET quantification in cardiovascular imaging. Clin Transl Imaging. 2014;2:343-58. https://doi.org/10.1007/s40336-014-0070-2.

62. Kuruvilla S, Kramer CM. Coronary microvascular dysfunction in women: an overview of diagnostic strategies. Expert Rev Cardiovasc Ther. 2013;11:1515-25. https://doi.org/10.1586/14779072.2013.833854

63. Nel K, Nam MCY, Anstey C, Boos CJ, Carlton E, Senior R, Kaski JC, Khattab A, Shamley D, Byrne CD, Stanton T, Greaves K. Myocardial blood flow reserve is impaired in patients with aortic valve calcification and unobstructed epicardial coronary arteries. Int J Cardiol. 2017;248:427-32. https://doi.org/10.1016/j.ijcard.2017.06.023.

64. Kato S, Saito N, Kirigaya H, Gyotoku D, linuma N, Kusakawa Y, Iguchi K, Nakachi T, Fukui K, Futaki M, Iwasawa T, Kimura K, Umemura S. Impairment of coronary flow reserve evaluated by phase contrast cine-magnetic resonance imaging in patients with heart failure with preserved ejection fraction. J Am Heart Assoc. 2016;5:1-9. https://doi.org/10.1161/ JAHA.115.002649.

65. Sade LE, Eroglu S, Bozbaş H, Özbiçer S, Hayran M, Haberal A, Müderrisoğlu $\mathrm{H}$. Relation between epicardial fat thickness and coronary flow reserve in women with chest pain and angiographically normal coronary arteries. Atherosclerosis. 2009;204:580-5. https://doi.org/10.1016/j.atherosclerosis. 2008.09.038.

66. Hildick-Smith DJR, Johnson PJ, Wisbey CR, Winter EM, Shapiro LM. Coronary flow reserve is supranormal in endurance athletes: an adenosine transthoracic echocardiographic study. Heart. 2000;84:383-9. https://doi. org/10.1136/heart.84.4.383.

67. Hozumi T, Yoshida K, Akasaka T, Asami Y, Ogata Y, Takagi T, Kaji S, Kawamoto T, Ueda Y, Morioka S. Noninvasive assessment of coronary flow velocity and coronary flow velocity reserve in the left anterior descending coronary artery by Doppler echocardiography: comparison with invasive technique. J Am Coll Cardiol. 1998;32:1251-9. https://doi.org/10. 1016/S0735-1097(98)00389-1.

68. Shufelt CL, Thomson LEJ, Goykhman P, Agarwal M, Mehta PK, SedlakT, Li N, Gill E, Samuels B, Azabal B, Kar S, Kothawade K, Minissian M, Slomka P, Berman DS, Bairey Merz CN. Cardiac magnetic resonance imaging myocardial perfusion reserve index assessment in women with microvascular coronary dysfunction and reference controls. Cardiovasc Diagn Ther. 2013;3:153-15360. https://doi.org/10.3978/j.issn.2223-3652.2013.08.02. 
69. Vasu S, Bandettini WP, Hsu LY, Kellman P, Leung S, Mancini C, Shanbhag SM, Wilson J, Booker OJ, Arai AE. Regadenoson and adenosine are equivalent vasodilators and are superior than dipyridamole-a study of first pass quantitative perfusion cardiovascular magnetic resonance. J Cardiovasc Magn Reson. 2013;15:1-9. https://doi.org/10.1186/1532-429X-15-85.

70. Lim HE, Shim WJ, Rhee H, Kim SM, Hwang GS, Kim YH, Seo HS, Oh DJ, Ro YM. Assessment of coronary flow reserve with transthoracic Doppler echocardiography: comparison among adenosine, standard-dose dipyridamole, and high-dose dipyridamole. J Am Soc Echocardiogr. 2000;13:264-70. https://doi.org/10.1067/mje.2000.103508.

71. Opstal T, Knol R, Cornel J, Wondergem M, Van der Zant F. Myocardial blood flow and myocardial flow reserve values in $13 \mathrm{~N}$-ammonia myocardial perfusion PET/CT using a time-efficient protocol in patients without coronary artery disease. Eur J Hybrid Imaging. 2018;2:11. https://doi.org/ 10.1186/s41824-018-0029-z.

72. Chareonthaitawee P, Kaufmann PA, Rimoldi O, Camici PG. Heterogeneity of resting and hyperemic myocardial blood flow in healthy humans. Cardiovasc Res. 2001;50:151-61. https://doi.org/10.1016/S0008-6363(01) 00202-4.

73. Waheed N, Elias-Smale S, Malas W, Maas AH, Sedlak TL, Tremmel J, Mehta PK. Sex differences in non-obstructive coronary artery disease. Cardiovasc Res. 2020;116:829-40. https://doi.org/10.1093/cvr/cvaa001.

74. Safdar B, D'Onofrio G, Dziura J, Russell RR, Johnson C, Sinusas AJ. Prevalence and characteristics of coronary microvascular dysfunction among chest pain patients in the emergency department. Eur Heart J Acute Cardiovasc Care. 2020;9:5-13. https://doi.org/10.1177/2048872618764418.
75. Taqui S, Ferencik M, Davidson BP, Belcik JT, Moccetti F, Layoun M, Raber J, Turker M, Tavori H, Fazio S, Lindner JR. Coronary microvascular dysfunction by myocardial contrast echocardiography in nonelderly patients referred for computed tomographic coronary angiography. J Am Soc Echocardiogr. 2019;32:817-25. https://doi.org/10.1016/j.echo.2019.03. 001.

76. Rinkevich D, Belcik T, Gupta NC, Cannard E, Alkayed NJ, Kaul S. Coronary autoregulation is abnormal in syndrome $\mathrm{X}$ : Insights using myocardial contrast echocardiography. J Am Soc Echocardiogr. 2013;26:290-6. https://doi.org/10.1016/j.echo.2012.12.008.

77. Bechsgaard DF, Gustafsson I, Michelsen MM, Mygind ND, Raft KF, Linde JJ, Kofoed KF, Lin FYH, Min JK, Prescott E, Hove JD. Evaluation of computed tomography myocardial perfusion in women with angina and no obstructive coronary artery disease. Int J Cardiovasc Imaging. 2020;36:367-82. https://doi.org/10.1007/s10554-019-01723-5.

78. Engblom H, Xue H, Akil S, Carlsson M, Hindorf C, Oddstig J, Hedeer F, Hansen MS, Aletras AH, Kellman P, Arheden H. Fully quantitative cardiovascular magnetic resonance myocardial perfusion ready for clinical use: a comparison between cardiovascular magnetic resonance imaging and positron emission tomography. J Cardiovasc Magn Reson. 2017;19:1-9. https://doi.org/10.1186/s12968-017-0388-9.

\section{Publisher's Note}

Springer Nature remains neutral with regard to jurisdictional claims in published maps and institutional affiliations.
Ready to submit your research? Choose BMC and benefit from:

- fast, convenient online submission

- thorough peer review by experienced researchers in your field

- rapid publication on acceptance

- support for research data, including large and complex data types

- gold Open Access which fosters wider collaboration and increased citations

- maximum visibility for your research: over $100 \mathrm{M}$ website views per year

At BMC, research is always in progress.

Learn more biomedcentral.com/submissions 